\title{
Patient preference: messages for the wider adoption of renal denervation in the real world
}

\author{
Tzung-Dau Wang'
}

Received: 29 November 2021 / Accepted: 30 November 2021 / Published online: 24 December 2021

(c) The Japanese Society of Hypertension 2021

Hypertension is the most important attributable cause of cardiovascular diseases worldwide [1-3]. Although there are many effective and well-tolerated antihypertensive medications, the control rates among hypertensive patients remain disappointing, below $25 \%$ globally $[1,3]$. Among the various causes of suboptimal control, non-adherence to medications is the most essential one [4]. Non-adherence influences not only hypertension control, but also the management of all non-communicable chronic diseases [5]. Non-adherence is the inherent limitation of medications, which should be taken regularly to action. Non-adherence is not entirely due to forgetfulness, but also, at least in part, implies patient preference. In contrast to medication control, device therapy of hypertension, like renal denervation, confers sustained blood pressure control and is free of the concern of non-adherence [6]. However, the invasive nature and varied blood pressure-lowering responses are disadvantages of device therapy and may impact patient preference [7]. Patient preference has been emphasized to be considered during hypertension treatment strategy determination through shared decision making in almost all recently published consensus documents or position papers on renal denervation [7-10]. Patient preference is built on the received medical information and his or her perceptions about the information. Therefore, valid, unbiased, and updated medical information disclosure is of utmost importance during shared decision-making process, instead of emphasizing patient preference alone, which could be easily misguided [11]. Choosing Wisely UK advocates use of the BRAN (benefits, risks, alternatives, nothing) tool to establish patient preference on a scientifically sound

Tzung-Dau Wang

tdwang@ntu.edu.tw

1 Cardiovascular Center and Divisions of Cardiology and Hospital Medicine, Department of Internal Medicine, National Taiwan University Hospital and National Taiwan University College of Medicine, Taipei City, Taiwan basis [12]. Within the framework of BRAN, short-term and long-term effects, as well as economic considerations, of strategies consulted should be provided in share-decision making.

Prior studies regarding patient preference for renal denervation and pharmacological therapy for hypertension are limited. One was based on 1011 patients in Germany [13], the other was based on 2768 patients in Western Europe and the United States [14]. In this issue of the Journal, Kario et al reported patient preference for renal denervation according to nationwide web-based survey in 2392 patients in Japan [15]. All these studies were done without presurvey education of updated medical information of renal denervation, thus, not a qualified setting for shared decision making for consultation for renal denervation. However, the responses from participants reflected what renal denervation was perceived by the public. Results from the three surveytype investigations are surprisingly similar. First, among patients undertaking the survey, 30-50\% would prefer renal denervation as the treatment strategy for hypertension. Second, patients who were pro-renal denervation were younger, more often male, and less adherent to medications and had more antihypertensive drug-related side effects. The number of antihypertensive medications did not impact the willingness to undergo renal denervation. Patients with higher on-treatment blood pressures were more prone to renal denervation in Japan [15], whereas this trend was not evident in patients surveyed in Western Europe and the United States [14]. Third, instead of the relatively positive attitudes towards renal denervation, the expectations for renal denervation on blood pressure-lowering from patients were high. Among patients surveyed in Japan and Germany, $40 \%$ expected renal denervation could achieve systolic blood pressure reduction of at least $15 \mathrm{mmHg}$, whereas few than $10 \%$ of patients accepted a systolic blood pressure reduction of less than $10 \mathrm{mmHg}$ with renal denervation. Further, only $4 \%$ of Germany patients agreed to undergo renal denervation if the probability of blood pressure reduction of $\geq 10 \mathrm{mmHg}$ is $<80 \%$ [13]. 
The consistent findings from the three surveys could partly explain the slow uptake of renal denervation worldwide: there is still a gap between the expected blood pressure reductions and what was observed in randomized clinical trials [6]. However, the blood pressure reductions achieved in real-world registries [16], particularly in Asian populations [17-19], were similar to what was expected in the surveys. In addition to office blood pressure reductions, renal denervation could confer greater reductions in asleep pressures, blood pressure fluctuations, and ambulatory blood pressure reductions, all of which are of potential prognostic significance [8]. A recent study showed that, among 296 patients treated with renal denervation, 180 patients with 24-h ambulatory systolic blood pressure reduction of $\geq 5 \mathrm{mmHg}$ at 3 months had a $47 \%$ reduction in major adverse cardiovascular events, compared to those with $<5 \mathrm{mmHg}$ reduction, during a median follow-up of 48 months [20]. All these updated information should be provided to patients consulted for renal denervation before assessing patient preference. On the other hand, the surveys pointed out that current knowledge gaps in renal denervation including clinical or intra-procedural predictors for responders or even super-responders need to filled to lessen uncertainty about its potentially powerful blood pressurelowering efficacy.

\section{Compliance with ethical standards}

Conflict of interest The author declares no competing interests.

Publisher's note Springer Nature remains neutral with regard to jurisdictional claims in published maps and institutional affiliations.

\section{References}

1. Collaboration NCDRF. Worldwide trends in hypertension prevalence and progress in treatment and control from 1990 to 2019: A pooled analysis of 1201 population-representative studies with 104 million participants. Lancet. 2021;398:957-80.

2. Lin HJ, Wang TD, Yu-Chih Chen M, Hsu CY, Wang KL, Huang $\mathrm{CC}$, et al. 2020 consensus statement of the taiwan hypertension society and the taiwan society of cardiology on home blood pressure monitoring for the management of arterial hypertension. Acta Cardiol Sin. 2020;36:537-61.

3. Pan HY, Lin HJ, Chen WJ, Wang TD. Prevalence, treatment, control and monitoring of hypertension: a nationwide communitybased survey in taiwan, 2017. Acta Cardiol Sin. 2020;36:375-81.

4. Wang TD, Chen YH, Huang CH, Chen WJ, Chen MF. Bidirectional adherence changes and associated factors in patients switched from free combinations to equivalent single-pill combinations of antihypertensive drugs. Hypertension. 2014;63:958-67.

5. Lin JL, Huang PH, Yeh HI, Li YH. Appropriate use of proprotein convertase subtilisin/kexin type 9 (PCSK9) inhibitors for atherosclerotic cardiovascular disease: Comparison of recommendations from different guidelines or consensus around the world. Acta Cardiol Sin. 2020;36:403-08.

6. Ogoyama Y, Tada K, Abe M, Nanto S, Shibata H, Mukoyama M, et al. Effects of renal denervation on blood pressures in patients with hypertension: a systematic review and meta-analysis of randomized sham-controlled trials. Hypertens Res. 2021, https:// doi.org/10.1038/s41440-021-00761-8.

7. Wang TD, Lee YH, Chang SS, Tung YC, Yeh CF, Lin YH, et al. 2019 consensus statement of the Taiwan Hypertension Society and the Taiwan Society of Cardiology on renal denervation for the management of arterial hypertension. Acta Cardiol Sin. 2019;35:199-230.

8. Kario K, Kim BK, Aoki J, Wong AY, Lee YH, Wongpraparut N, et al. Renal denervation in Asia: consensus statement of the Asia Renal Denervation Consortium. Hypertension 2020;75:590-602.

9. Kandzari DE, Townsend RR, Bakris G, Basile J, Bloch MJ, Cohen DL, et al. Renal denervation in hypertension patients: proceedings from an expert consensus roundtable cosponsored by SCAI and NKF. Catheterization Cardiovasc Interv. 2021;98:416-26.

10. Schmieder RE, Mahfoud F, Mancia G, Azizi M, Bohm M, Dimitriadis K, et al. European Society of Hypertension position paper on renal denervation 2021. J Hypertens. 2021;39:1733-41.

11. Whelton PK, Carey RM, Aronow WS, Casey DE Jr, Collins KJ, Dennison Himmelfarb C, et al. 2017 acc/aha/aapa/abc/acpm/ags/ apha/ash/aspc/nma/pcna guideline for the prevention, detection, evaluation, and management of high blood pressure in adults: a report of the American College of Cardiology/American Heart Association task force on clinical practice guidelines. Hypertension. 2018;71:e13-e115.

12. Barnett G, Swart M. Shared decision making for high-risk surgery. BJA Educ. 2021;21:300-06.

13. Schmieder RE, Hogerl K, Jung S, Bramlage P, Veelken R, Ott C. Patient preference for therapies in hypertension: a cross-sectional survey of German patients. Clin Res Cardiol. 2019;108:1331-42.

14. Schmieder RE, Kandzari DE, Wang TD, Lee YH, Lazarus G, Pathak A. Differences in patient and physician perspectives on pharmaceutical therapy and renal denervation for the management of hypertension. J Hypertens. 2021;39:162-68.

15. Kario K, Kagitani H, Hayashi S, Hanamura S, Ozawa K, Kanegae H. A Japan nationwide web-based survey of patient preference for renal denervation for hypertension treatment. Hypertens Res. 2021, https://doi.org/10.1038/s41440-021-00760-9.

16. Mahfoud F, Mancia G, Schmieder R, Narkiewicz K, Ruilope L, Schlaich M, et al. Renal denervation in high-risk patients with hypertension. J Am Coll Cardiol. 2020;75:2879-88.

17. Lee CK, Wang TD, Lee YH, Fahy M, Lee CH, Sung SH, et al. Efficacy and safety of renal denervation for patients with uncontrolled hypertension in Taiwan: 3-year results from the Global Symplicity Registry-Taiwan (GSR-Taiwan). Acta Cardiol Sin. 2019;35:618-26.

18. Kario K, Yamamoto E, Tomita H, Okura T, Saito S, Ueno T, et al. Sufficient and persistent blood pressure reduction in the final longterm results from Symplicity HTN-Aapan- safety and efficacy of renal denervation at 3 years. Circ J. 2019;83:622-29.

19. Kim BK, Kim HS, Park SJ, Park CG, Seung KB, Gwon HC, et al. Long-term outcomes after renal denervation in an Asian population: results from the Global Symplicity Registry in South Korea (GSR Korea). Hypertens Res. 2021;44:1099-104.

20. Fengler K, Reimann P, Rommel KP, Kresoja KP, Blazek S, Unterhuber $\mathrm{M}$, et al. Comparison of long-term outcomes for responders versus non-responders following renal denervation in resistant hypertension. J Am Heart Assoc. 2021;10:e022429. 